\title{
Durability of Modified Expanded Polystyrene Concrete after Dynamic Cyclic Loading
}

\author{
Wenbo Shi, Linchang Miao, Junhui Luo, Jiaqi Wang, and Yinan Chen \\ Institute of Geotechnical Engineering, Southeast University, Nanjing 210018, China \\ Correspondence should be addressed to Linchang Miao; lc.miao@seu.edu.cn
}

Received 2 July 2015; Revised 28 October 2015; Accepted 29 October 2015

Academic Editor: Salvatore Russo

Copyright ( 2016 Wenbo Shi et al. This is an open access article distributed under the Creative Commons Attribution License, which permits unrestricted use, distribution, and reproduction in any medium, provided the original work is properly cited.

\begin{abstract}
EPS concrete was produced by mixing the expanded polystyrene spheres (EPS) and polymer emulsion and thickener to the matrix concrete, and this concrete had good vibration energy absorption characteristics. Based on the experimental data obtained on EPS volume ratio of $0 \%, 20 \%, 30 \%$, and $40 \%$ by replacing matrix or coarse aggregate, the two design styles had nearly the same compressive strength. By applying frequency of $5 \mathrm{~Hz}, 50000$ or 100000 times, $40 \mathrm{KN}, 50 \mathrm{KN}$, and $60 \mathrm{KN}$ cyclic loading, it is shown that the higher the inclusion size was, the lower the compressive strength of the EPS concrete would be; the larger the applying dynamic cyclic load was, the more obvious the compressive strength changing would be. Meanwhile, the strength of EPS concrete had no evident change after durability test. The results of this research had practical significance on using EPS concrete in some long-term cyclic dynamic load engineering.
\end{abstract}

\section{Introduction}

Because the expanded polystyrene (EPS) light weight concrete has the characteristics of lightweight, energy absorption, and heat preservation, it is used in many specific construction industries like high rise buildings, floating marine platforms, and large-sized and long-span concrete $[1,2]$. The lightweight concrete (LWC) has no pollution to the environment because manufacture EPS particle consumes little energy, and the particle has no poison and harm. The EPS concrete has the characteristics of economy, environmental protection, and energy saving, meeting the design concept of modern construction material.

In 1970s, Cook [3] put EPS particle into concrete and made research on it. The systematic research began in 1990s; French scholar obtained the relationship between strength of light weight concrete and porosity by putting different proportions of EPS particle into concrete [4]. The EPS concrete was produced by replacing the partially normal aggregates in concrete; the specific mix stage was depending upon the requirements of density and strength levels. The relationship between the strength and a wide range of density of the EPS concrete could be obtained by changing the mix scale of the EPS particle $[1,4-8]$. Also there have been some researches focused on the influence of expanded polystyrene particles size to the concrete compressive strength $[9,10]$. Styrene-butadiene rubber (SBR) latex was applied in EPS concrete as a polymeric admixture by Chen and Liu [11] to improve the homogeneity of the EPS particle in LWC and make sure the particle will not float during the concrete vibration. Babu et al. [12] increased the strength by mixing the fly ash into the EPS concrete and improved the early strength by mixing the silica fume into the EPS concrete [13]. With an introduction of a premix method utilized to make the EPS concrete by Chen and Liu [14], it avoided segregation of the EPS particles in the aggregate during casting. Laalai and Sab [15] verified the transformation formula among different specimen sizes.

EPS concrete has been considered as an energy-absorbing material for the protection of buried military structure and some specific constructions which suffer long-term cyclic loading. Meanwhile, it has requirements for strength and durability of EPS concrete. The main purpose of this paper is to quantify the influence of the EPS concrete inclusion size on compressive strength, improving the strength and the workability of the EPS concrete by mixing three admixtures. 


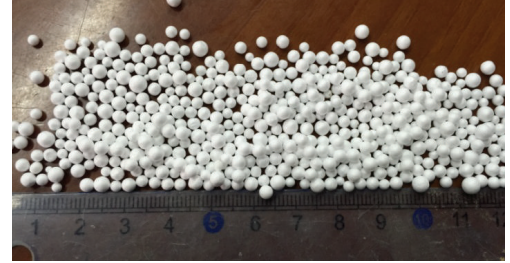

FIGURE 1: Expanded polystyrene spheres.

The durability of the EPS concrete was obtained by making comparison between specimen before and after applying cyclic load of $40 \mathrm{KN}, 50 \mathrm{KN}$, and $60 \mathrm{KN}$ for 50000 or 10000 times.

\section{Materials and Mix Design Principles}

The test specimens were made with the same type as that used for very high strength concrete, and the EPS particle took the place of part of the concrete or coarse aggregate.

(1) Cement. It was made with CEM I 52.5 cement.

(2) Fine Aggregate. It is made with rounded river sand with a fineness modulus of 2.85 .

(3) Coarse Aggregate. It is gravel with a diameter range of 4$20 \mathrm{~mm}$.

(4) EPS Particles. EPS particles are expanded polystyrene spheres particle with a diameter range of $1-3 \mathrm{~mm}$ and density of $20 \mathrm{~kg} / \mathrm{m}^{3}$ which is shown in Figure 1.

(5) Silica Fume. Because the fineness of silica fume is very low, it is about 80-100 compared to normal cement and it is used in the concrete to fill up the pore among the cement granules and the hydrate products are similar to cement in water; the other mixture would been bonded by the gel. The mixing ratio of the silica fume is discussed by K. G. Babu and D. S. Babu [13].

(6) Admixture. A polycarboxylate-based superplasticizer was used to improve the workability and the compressive strength of the EPS concrete and the mixing ratio refers to the result of Miled et al. [4]. Expanded polystyrene spheres particles are hydrophobic material, extremely light with the density of only $12-20 \mathrm{~kg} / \mathrm{m}^{3}$ which can cause segregation in mixing and make the inhomogeneity of the EPS concrete, leading to the decrease of the compressive strength.

There are two ways to approach this issue: one is to increase the bond action between the EPS particles and aggregates by transforming the EPS particles from hydrophobic material to hydrophilic material and the other is to improve the viscosity of the EPS concrete. In order to improve the compressive strength of the EPS concrete as much as possible, the specimen was made by adopting both methods. Polymer emulsion was mixed in the mixture to increase the viscidity; the relationship between compressive strength and mixing

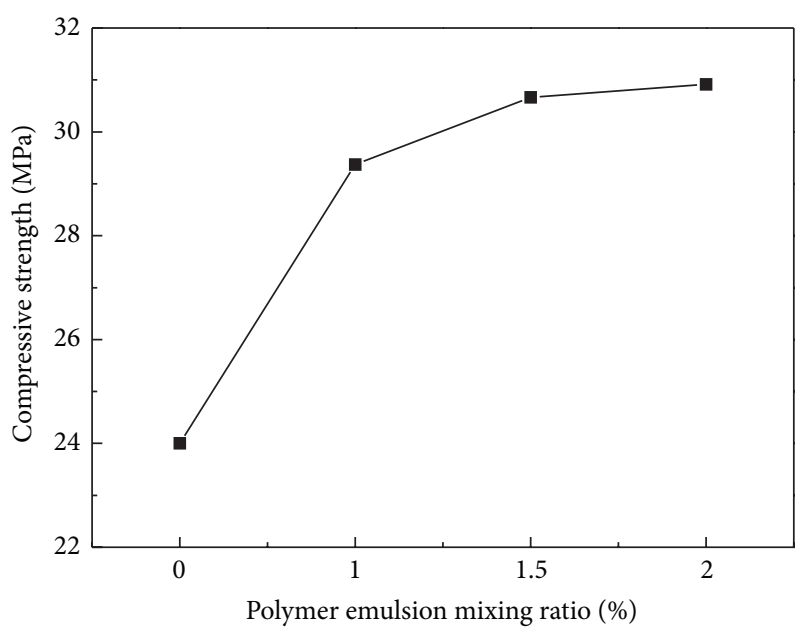

FIGURE 2: The relationship between compressive strength and polymer emulsion mixing ratio.

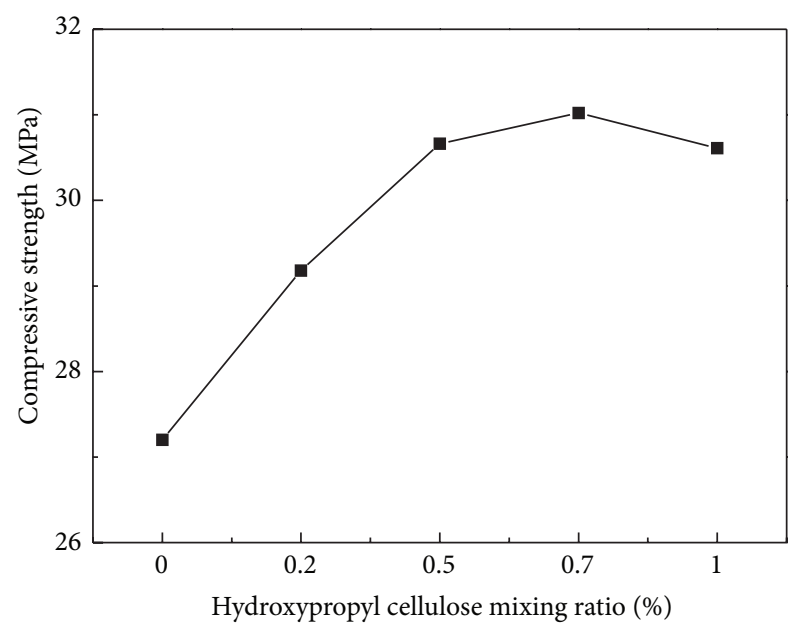

FIGURE 3: The relationship between compressive strength and hydroxypropyl cellulose mixing ratio.

ratio is shown in Figure 2. The hydroxypropyl cellulose ether was used as to control the consistence and water retention capacity of the concrete slurry; the relationship between compressive strength and mixing ratio is shown in Figure 3. The two admixtures could make sure that the EPS particles would not segregate during the concrete vibration.

(7) Mixing Method. Because of the hydrophobic material of the EPS particles, the workability and durability of EPS concrete were poor during the mixing process [16]. Indeed, after numerous mixing, a mixing method similar to the "sandwrapping" technique was utilized to make EPS concrete. Firstly, it pulled the EPS particles and 1/3 water and 1/2 polymer emulsion into the mixed hopper. After mixing of one minute, it introduced the gravel into the mixed hopper and then mixed it for one minute and finally it pulled all the other aggregates into the mixed hopper and mixed them for two minutes. The mixing method would ensure the workability and homogeneousness of the EPS concrete. 
TABLE 1: Proportion of EPS concrete mixes.

\begin{tabular}{|c|c|c|c|c|c|c|c|c|c|c|}
\hline $\begin{array}{l}\text { EPS } \\
\text { volume } \\
\text { ratio\% }\end{array}$ & $\begin{array}{l}\text { Design } \\
\text { type }\end{array}$ & $\begin{array}{l}\text { Water/ } \\
\text { cement } \\
\text { ratio\% }\end{array}$ & $\begin{array}{l}\text { Cement } \\
\mathrm{kg} / \mathrm{m}^{3}\end{array}$ & $\begin{array}{c}\text { River } \\
\text { sand } \\
\mathrm{kg} / \mathrm{m}^{3}\end{array}$ & $\begin{array}{l}\text { Gravel } \\
\mathrm{kg} / \mathrm{m}^{3}\end{array}$ & $\begin{array}{l}\text { Water } \\
\mathrm{kg} / \mathrm{m}^{3}\end{array}$ & $\begin{array}{l}\text { Silica } \\
\text { fume } \\
\mathrm{kg} / \mathrm{m}^{3}\end{array}$ & $\begin{array}{l}\text { Superplasticizer } \\
\mathrm{kg} / \mathrm{m}^{3}\end{array}$ & $\begin{array}{c}\text { Polymer } \\
\text { emulsion } \\
\mathrm{kg} / \mathrm{m}^{3}\end{array}$ & $\begin{array}{c}\text { hydroxypropyl } \\
\text { cellulose } \\
\mathrm{kg} / \mathrm{m}^{3}\end{array}$ \\
\hline 0 & $\begin{array}{c}\text { No } \\
\text { replacing }\end{array}$ & 32 & 538 & 542 & 1152 & 172 & 26.9 & 8.07 & 8.07 & 2.69 \\
\hline 0.2 & $\begin{array}{l}\text { Replace the } \\
\text { concrete }\end{array}$ & 32 & 430 & 434 & 922 & 138 & 21.52 & 6.456 & 6.456 & 2.152 \\
\hline 0.2 & $\begin{array}{l}\text { Replace the } \\
\text { gravel only }\end{array}$ & 32 & 538 & 542 & 662 & 172 & 26.9 & 8.07 & 8.07 & 2.69 \\
\hline 0.3 & $\begin{array}{l}\text { Replace the } \\
\text { concrete }\end{array}$ & 32 & 375 & 380 & 808 & 120 & 18.75 & 5.625 & 5.625 & 1.875 \\
\hline 0.3 & $\begin{array}{l}\text { Replace the } \\
\text { gravel only }\end{array}$ & 32 & 538 & 542 & 662 & 172 & 26.9 & 8.07 & 8.07 & 2.69 \\
\hline 0.4 & $\begin{array}{l}\text { Replace the } \\
\text { concrete }\end{array}$ & 32 & 323 & 325 & 691 & 103 & 16.14 & 4.842 & 4.842 & 1.614 \\
\hline 0.4 & $\begin{array}{l}\text { Replace the } \\
\text { gravel only }\end{array}$ & 32 & 538 & 542 & 172 & 172 & 26.9 & 8.07 & 8.07 & 2.69 \\
\hline
\end{tabular}

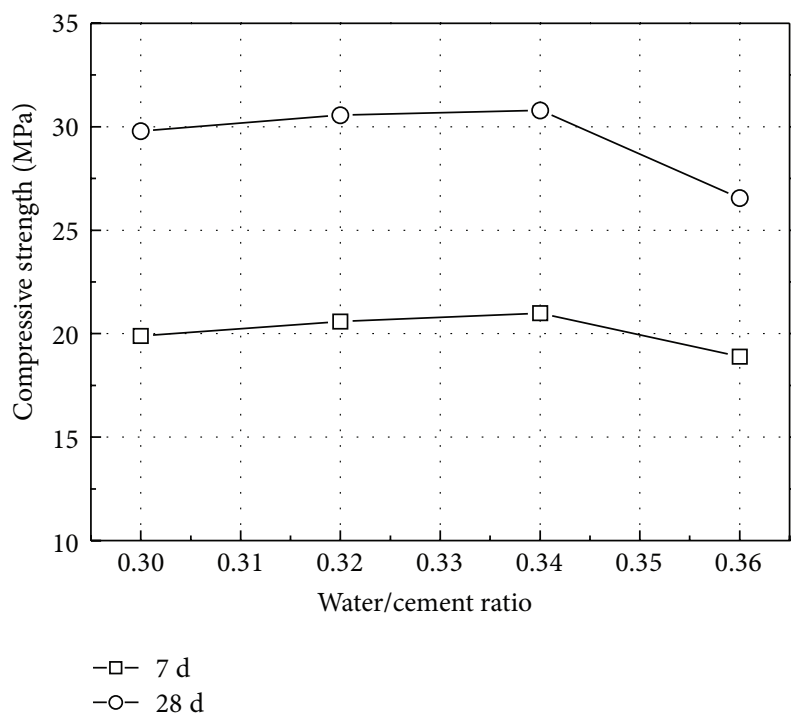

Figure 4: The influence of the water-cement ratio.

\section{Compressive Strength Test}

Cubes of $100 \mathrm{~mm}$ size of EPS concrete were used for studying the compressive strength after being stored in laboratory conditions for 28 days. Water-cement ratio is an important index to influence the compressive strength. The relationship between water-cement ratio and compressive strength is shown in Figure 4. The compressive strength significantly reduces as the water-cement ratio is set to 0.36 , because the EPS particles are of hydrophobic material and the workability falls when the water-cement ratio increases. The compressive strength changes slightly when the water-cement ratio increases from 0.32 to 0.34 , considering the economics as it applied to practical engineering the water-cement ratio is set to 0.32 in this paper.
In order to observe the influence of the EPS particle volume ratio on the compressive strength, various densities of the EPS concrete specimens were made according to Table 1.

The EPS volume ratio $p$ considered here as the concrete porosity was determined by the following formula [4]:

$$
p=\frac{\rho_{\text {matrix }}-\rho_{\text {concrete }}}{\rho_{\text {matrix }}-\rho_{\text {EPS }}}
$$

where $\rho_{\text {matrix }}$ is the densities of the matrix and $\rho_{\text {concrete }}$ and $\rho_{\text {EPS }}$ are the densities of EPS concrete and EPS particles, respectively.

Three specimens were made according to each design style and each value was reported because porosity and compressive strength of the specimen vary slightly. The effect of porosity on compressive strength of EPS lightweight concrete is shown in Figures 5 and 6

The minimum and maximum compressive strength of EPS concrete with the design style of EPS particles replacing concrete at the age of 28 days were 18.05 and $40.31 \mathrm{MPa}$; meanwhile, the minimum and maximum compressive strength were 16.23 and $40.07 \mathrm{MPa}$ following the design style of EPS particles replacing coarse aggregate from Figures 5 and 6 . It could be found that volume ratio of EPS had the most significant effect on the compressive strength of EPS replacing concrete or coarse aggregate and increase of EPS volume and decrease of the compressive strength.

According to the test value, the compressive strength of the two design styles was basically coinciding, but the porosity of the EPS concrete was different from Figures 5 and 6. In consideration of the economy in practical engineering, the cost of EPS particles replacing concrete was less and the compressive strength of this design style was the same as the EPS particles replacing coarse aggregate. Therefore, the research emphasis of this paper is to study the mechanical properties of EPS concrete with the EPS particles replacing the concrete. 


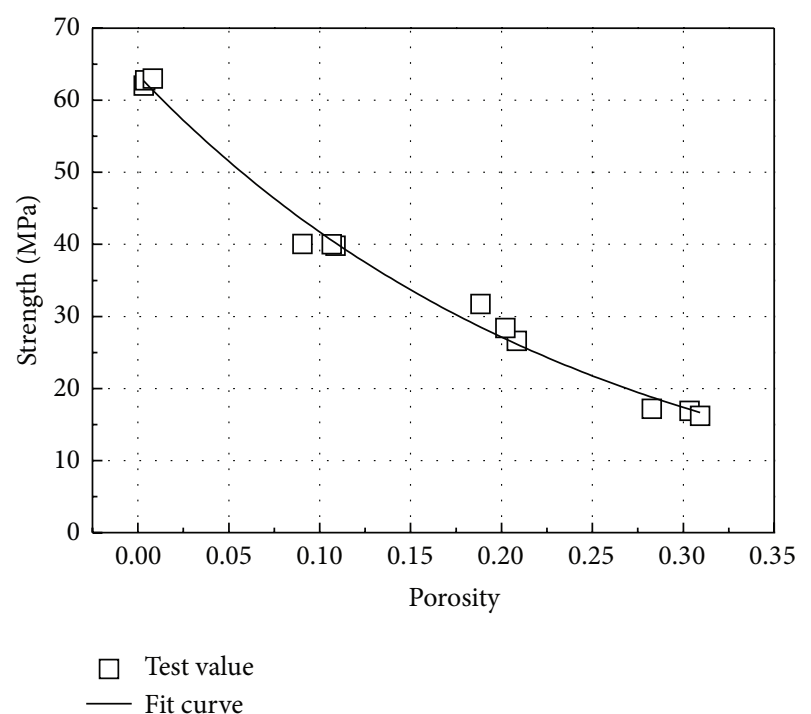

FIGURE 5: The variation of compressive strength of EPS particles replacing concrete with porosity.

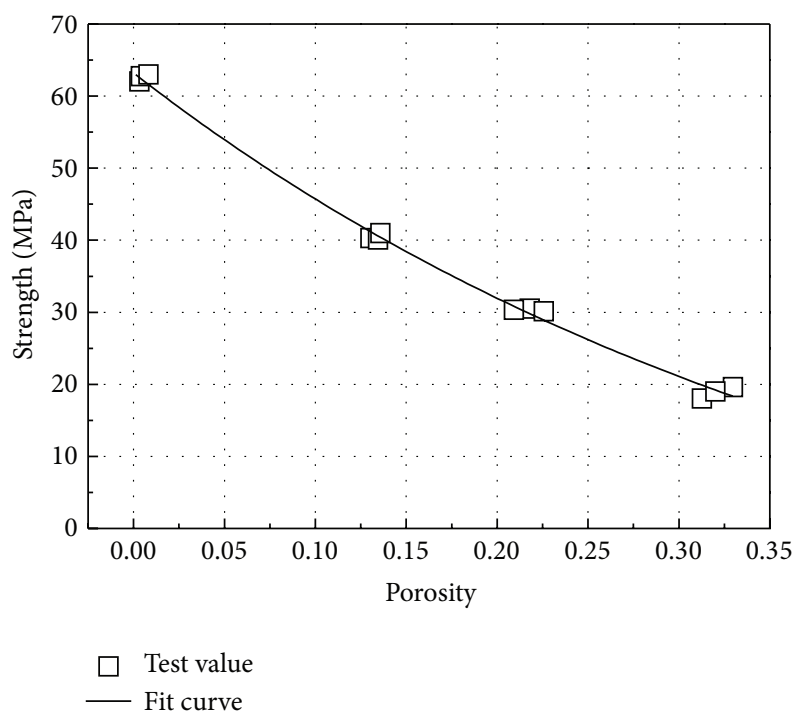

FIGURE 6: The variation of compressive strength of EPS particles replacing coarse aggregate with porosity.

Through exponential fit analysis, the empirical relations obtained can be written as

$$
f=82.27 \mathrm{e}^{-2.38 p}-19.05,
$$

where $f$ represent compressive strength (Mpa) at 28 days. Correlation coefficient $(R)$ of the proposed relation is 0.989 , indicating significant correlations.

Failure Mode. Different ratio of the EPS particles volume had different failure mode which is shown in Figure 7. The matrix was fracture after the compressive strength test, and the scale of crack was smaller along with the increase of the EPS particles volume ratio. This phenomenon was caused by the characteristics of energy absorption of EPS particles, and the appearance was still intact even if the EPS concrete was under destruction.

\section{The Durability of EPS Concrete}

EPS concrete has the characteristics of vibration resistance and energy absorption, which can be used in civil construction based on cycle loading to reduce vibration of system. However, it has great significance to test the durability of EPS concrete with vibration property since vibration load infliction often goes with the characteristic of low durability. This paper qualitatively analyzes the influence of EPS volume ratio, vibration cyclic times, and vibration load on EPS concrete durability by cycle loading test.

Cyclic dynamic vibration test used a 370.50 MTS electrohydraulic servo fatigue test system shown in Figure 8 which had $500 \mathrm{KN}$ load capacity and $150 \mathrm{~mm}$ dynamic travel and test data could be real-time shown and stored in the computer. EPS volume ratio was $0 \%, 20 \%, 30 \%$, and $40 \%$, times of vibration cycle were 50000 and 100000 , vibration load was $60 \mathrm{KN}, 50 \mathrm{KN}$, and $40 \mathrm{KN}$, and vibration frequency was $5 \mathrm{~Hz}$; the sine wave was adopted to simulate the vibration process.

4.1. 50000-Time Durability Test. After 50 thousand cyclic loading tests, the concrete would be in strength test; the value of the compressive strength before and after cyclic loading is shown in Figures 9-11.

The compressive strength of concrete without EPS particles decreased to different degree after durability test and the greater the cyclic loading applied, the more obvious the reduction of concrete strength. The compressive strength of $20 \%$ EPS particles volume ratio concrete (20\% EPS concrete) was less than before, while the compressive strength of 30\% and $40 \%$ EPS concrete are varying degrees of increase when applying $40 \mathrm{KN}$ cyclic load, mainly because cyclic loading led to EPS particles compression and the compaction of EPS concrete when applying load was small; therefore, the compressive strength of $30 \%$ and $40 \%$ EPS concrete was greater than before durability test. With applying load from $40 \mathrm{KN}$ to $50 \mathrm{KN}$ and finally to $60 \mathrm{KN}$, the influence of cyclic loading on durability of EPS concrete was becoming more and more obvious; meanwhile, the bigger the EPS particles volume ratio was, the smaller the compressive strength change after 50000 cyclic loading would be.

4.2. 100000-Time Durability Test. Because 100000-time cyclic dynamic test costs long time, the research took EPS concrete of particles volume ratio of $0 \%$ and $30 \%$ as an example by applying $50 \mathrm{KN}$ sinusoidal cyclic loading 100000 times on EPS concrete; the compressive strength before and after durability test is as shown in Figure 12.

The change of compressive strength of the matrix was obvious after 100000 times of dynamic vibration loading as is shown in Figure 12, while the compressive strength of $30 \%$ EPS concrete decreased in comparison with the strength after 50000-time cyclic dynamic vibration loading, but the reduction was not large; thus it could be concluded that EPS concrete is a kind of material which has good durability. 

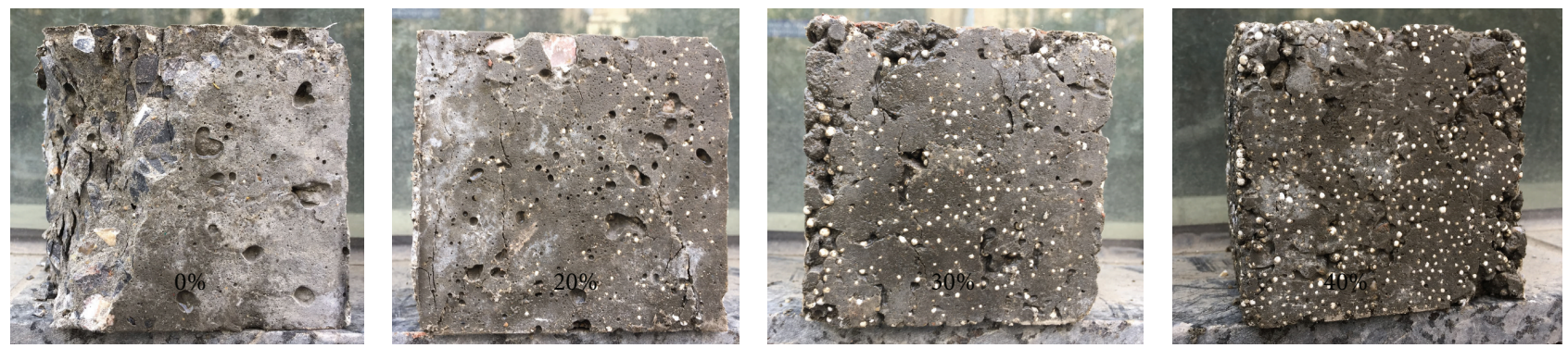

FIGURE 7: Failure mode of the EPS concrete with different EPS particles volume ratio.

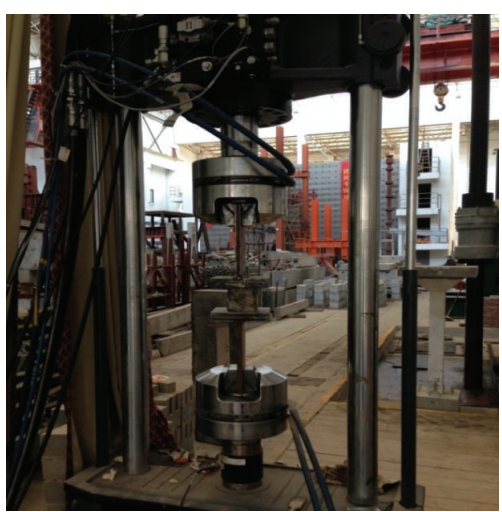

FigURE 8: MTS 370.50 dynamic test system.

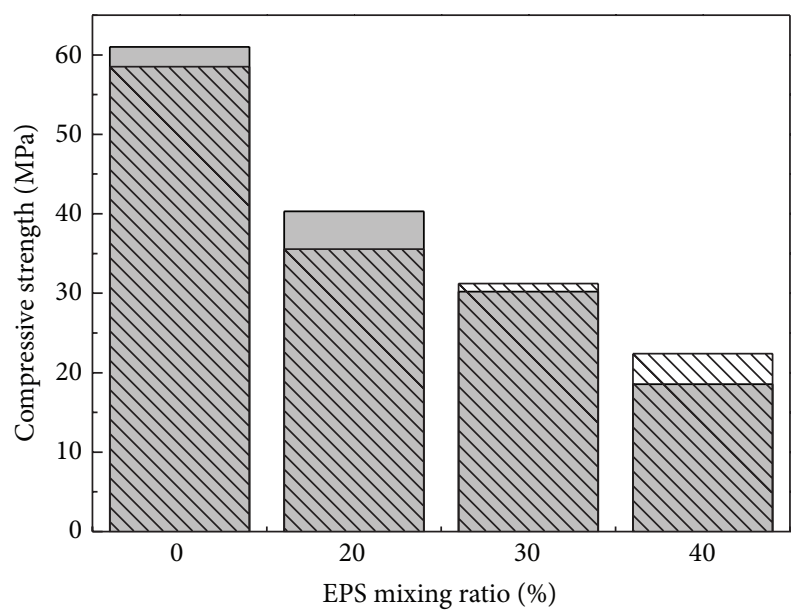

Before fatigue test

MIV After fatigue test

FIGURE 9: Later strength of $40 \mathrm{KN} 50000$-time cyclic loading.

\section{Conclusions}

EPS concrete has the advantages of small density, thermal insulation, and good seismic performance. So it is of great significance on the study of modern structural materials and practical engineering to research new concrete materials. The experimental investigations were conducted on three types of EPS concrete having EPS concrete of particles

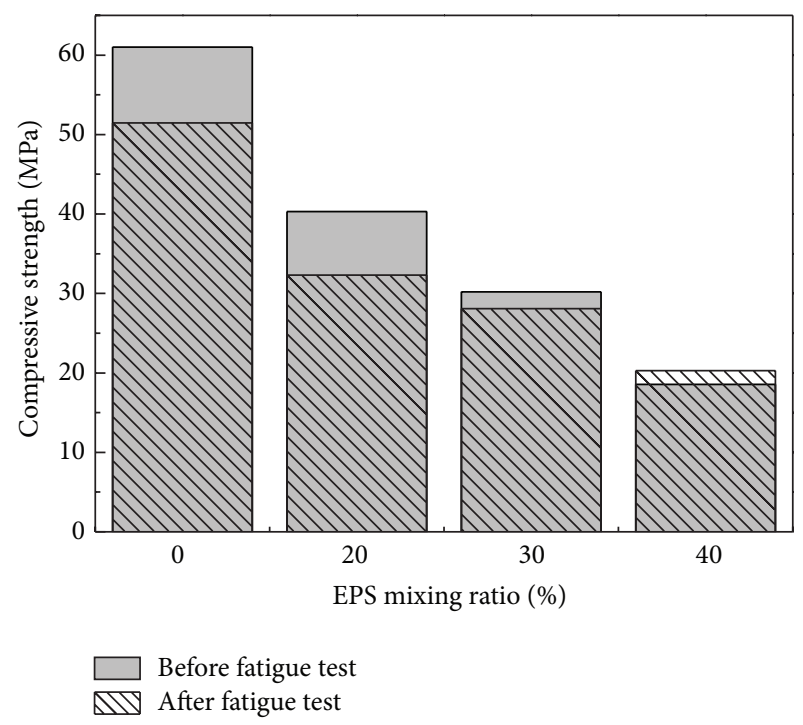

FIGURE 10: Later strength of $50 \mathrm{KN} 50000$-time cyclic loading.

volume ratio ranging from $0 \%$ to $40 \%$, with a view to confirming the presence of an intrinsic particle content effect on the EPS concrete compressive strength and durability. The conclusions are drawn as follows.

(1) In order to increase the compressive strength the polymer emulsion is mixing in the concrete grout which would bound other mixtures together, and the relationship between its mixing ratio and compressive strength is discussed. The hydroxypropyl cellulose is mixed in the EPS concrete for improving the workability of the grout and the influence of its mixing ratio on the concrete compressive strength is studied.

(2) The compressive strength of two types of EPS concrete in which concrete is replaced or only gravel replaced by EPS particles was basically identical; the result showed that the compressive strength of the two design styles was basically coinciding. The compressive strength of EPS concrete decreased obviously with the increase of EPS particles volume ratio; the reduction curve was similar to exponential type curve.

(3) The value of applying dynamic cyclic load had great effect on the compressive strength after durability 


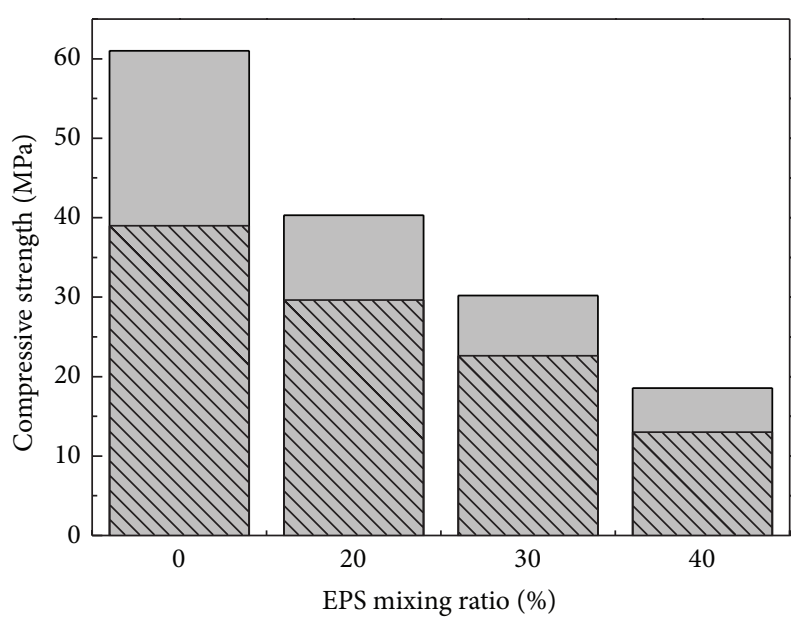

Before fatigue test MIV After fatigue test

FIGURE 11: Later strength of $60 \mathrm{KN} 50000$-time cyclic loading.

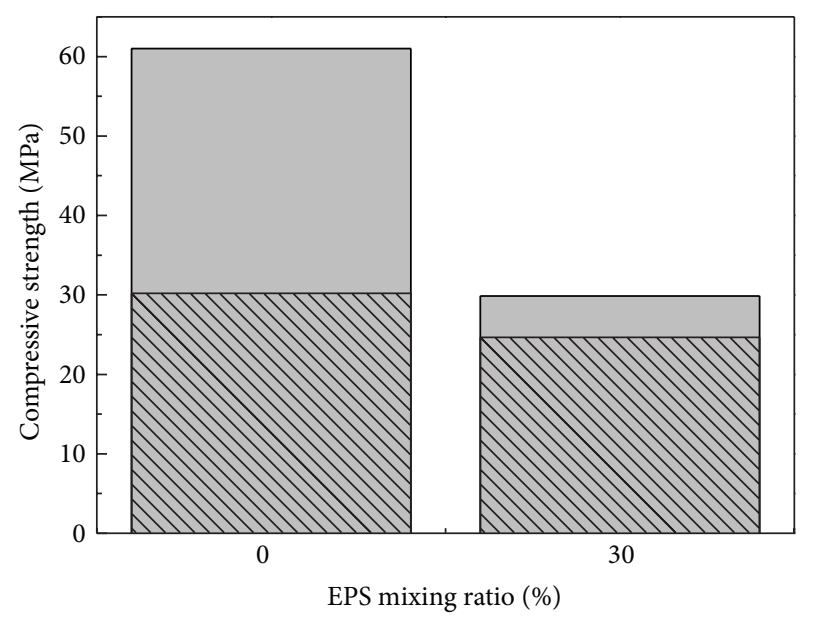

Before fatigue test MIV After fatigue test

FIGURE 12: Later strength of $50 \mathrm{KN} 100000$-time cyclic loading.

test. The compressive strength of EPS concrete of particles volume ratio of $40 \%$ was increased after applying $40 \mathrm{KN}$ and $50 \mathrm{KN}$ cyclic dynamic load, and the other ratio of EPS particles volume concrete was reduced after durability test; meanwhile, the degree of compressive strength reduction was inversely proportional to EPS particles volume ratio. Also, the bigger the applying dynamic cyclic load was, the bigger the gap of compressive strength between before and after durability test would be. The compressive strength of EPS concrete of particles volume ratio of $0 \%$ and $30 \%$ would fall when dynamic cyclic load is applied 100000 times, and the reduction of matrix compressive strength was much more bigger than EPS concrete particles volume ratio of $30 \%$ compared with applying dynamic vibration load 50000 times.

(4) Through the results from the designed durability test, it proved that the EPS lightweight concrete has good durability and it has a very good use in practical engineering which has certain seismic requirements and applied cyclic load.

\section{Conflict of Interests}

The authors declare that there is no conflict of interests regarding the publication of this paper.

\section{References}

[1] Y. Xu, L. Jiang, J. Xu, and Y. Li, "Mechanical properties of expanded polystyrene lightweight aggregate concrete and brick," Construction and Building Materials, vol. 27, no. 1, pp. 32-38, 2012.

[2] B. Chen and J. Liu, "Contribution of hybrid fibers on the properties of the high-strength lightweight concrete having good workability," Cement and Concrete Research, vol. 35, no. 5, pp. 913-917, 2005.

[3] D. J. Cook, Expanded Polystyrene Beads as Lightweight Aggregate for Concrete, School of Civil Engineering, University of New South Wales, 1972.

[4] K. Miled, K. Sab, and R. Le Roy, "Particle size effect on EPS lightweight concrete compressive strength: experimental investigation and modelling," Mechanics of Materials, vol. 39, no. 3, pp. 222-240, 2007.

[5] R. Le Roy, E. Parant, and C. Boulay, "Taking into account the inclusions' size in lightweight concrete compressive strength prediction," Cement and Concrete Research, vol. 35, no. 4, pp. 770-775, 2005.

[6] C. Bagon and S. Frondistou-Yannas, "Marine floating concrete made with polystyrene expanded beads," Magazine of Concrete Research, vol. 28, no. 97, pp. 225-229, 1976.

[7] R. Sri Ravindrarajah and A. J. Tuck, "Properties of hardened concrete containing treated expanded polystyrene beads," Cement and Concrete Composites, vol. 16, no. 4, pp. 273-277, 1994.

[8] G. C. Hoff, New Applications for Low-Density Concretes, vol. 29, ACI Special Publication, 1971.

[9] A. Laukaitis, R. Žurauskas, and J. Keriene, "The effect of foam polystyrene granules on cement composite properties," Cement and Concrete Composites, vol. 27, no. 1, pp. 41-47, 2005.

[10] E. Parant and R. Le Roy, "Optimisation des bétons de densité inférieure à," Tech. Rep., Laboratoire Central des Ponts et Chaussées, Paris, France, 1999.

[11] B. Chen and J. Liu, "Mechanical properties of polymer-modified concretes containing expanded polystyrene beads," Construction and Building Materials, vol. 21, no. 1, pp. 7-11, 2007.

[12] D. S. Babu, K. Ganesh Babu, and T. H. Wee, "Properties of lightweight expanded polystyrene aggregate concretes containing fly ash," Cement and Concrete Research, vol. 35, no. 6, pp. 1218-1223, 2005.

[13] K. G. Babu and D. S. Babu, "Behaviour of lightweight expanded polystyrene concrete containing silica fume," Cement and Concrete Research, vol. 33, no. 5, pp. 755-762, 2003. 
[14] B. Chen and J. Liu, "Properties of lightweight expanded polystyrene concrete reinforced with steel fiber," Cement and Concrete Research, vol. 34, no. 7, pp. 1259-1263, 2004.

[15] I. Laalai and K. Sab, "Size effect and stochastic nonlocal damage in quasi-brittle materials," in Probabilities and Materials, vol. 269 of NATO ASI, pp. 151-161, Springer, Amsterdam, The Netherlands, 1994.

[16] S. H. Perry, P. H. Bischoff, and K. Yamura, "Mix details and material behaviour of polystyrene aggregate concrete," Magazine of Concrete Research, vol. 43, no. 154, pp. 71-76, 1991. 


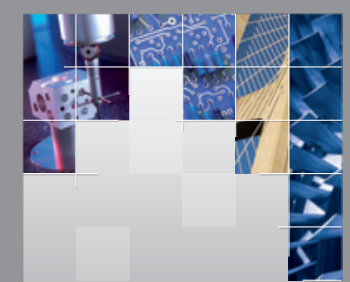

\section{Enfincering}
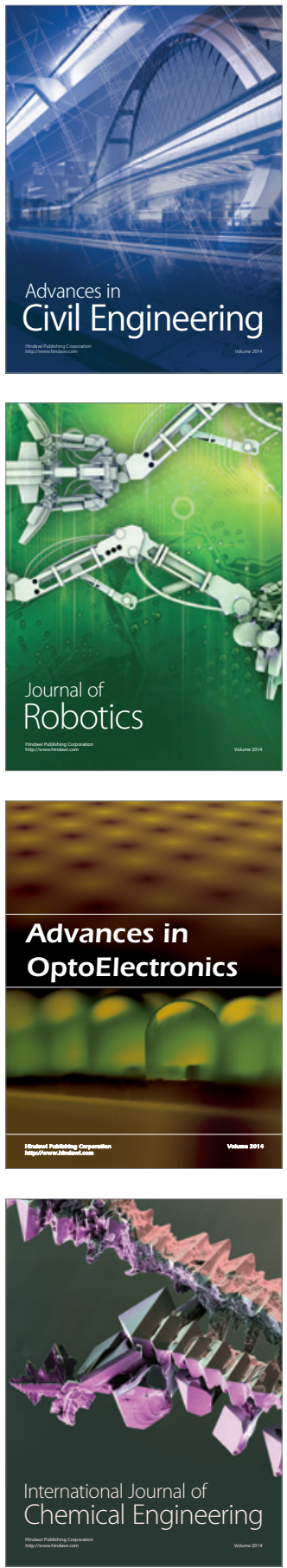

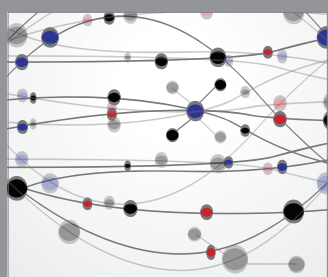

The Scientific World Journal

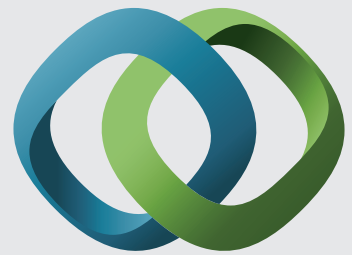

\section{Hindawi}

Submit your manuscripts at

http://www.hindawi.com
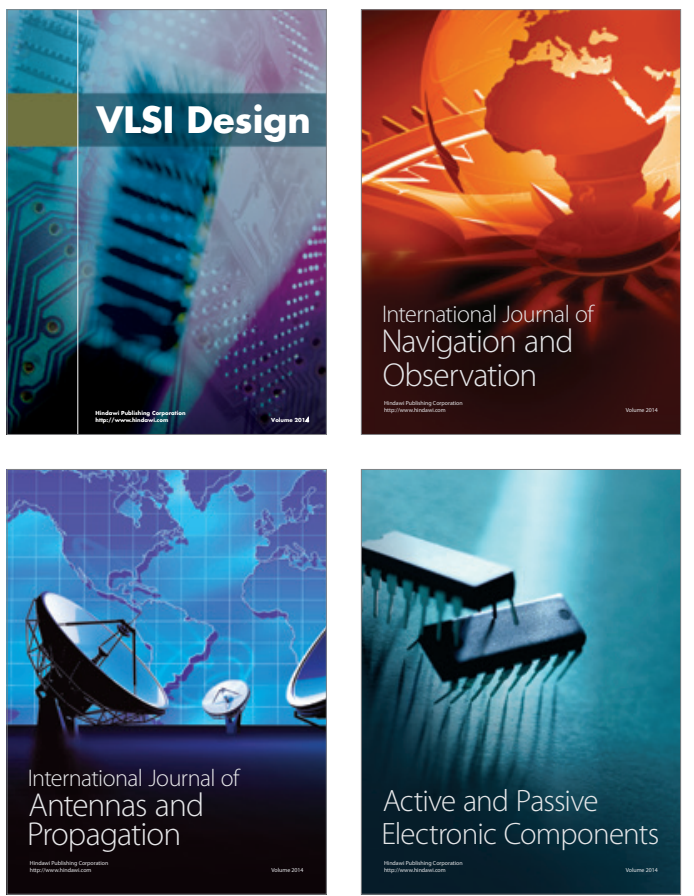
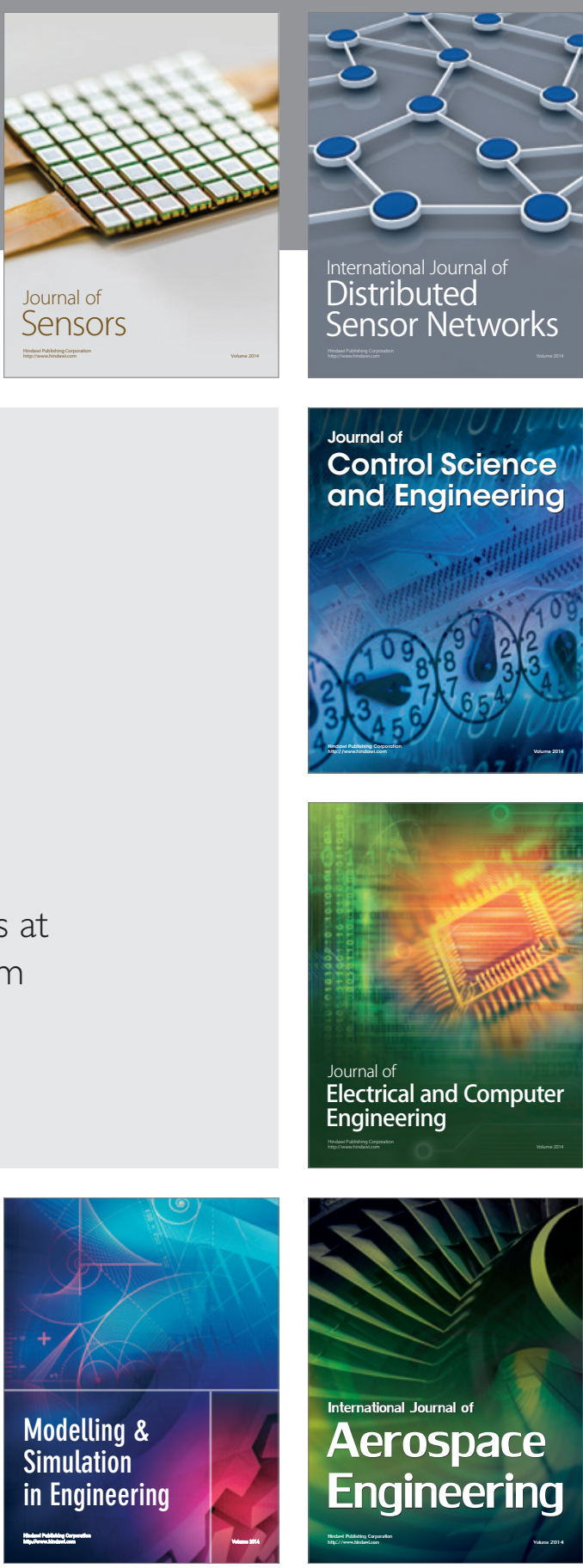

International Journal of

Distributed

Sensor Networks

Journal of

Control Science

and Engineering
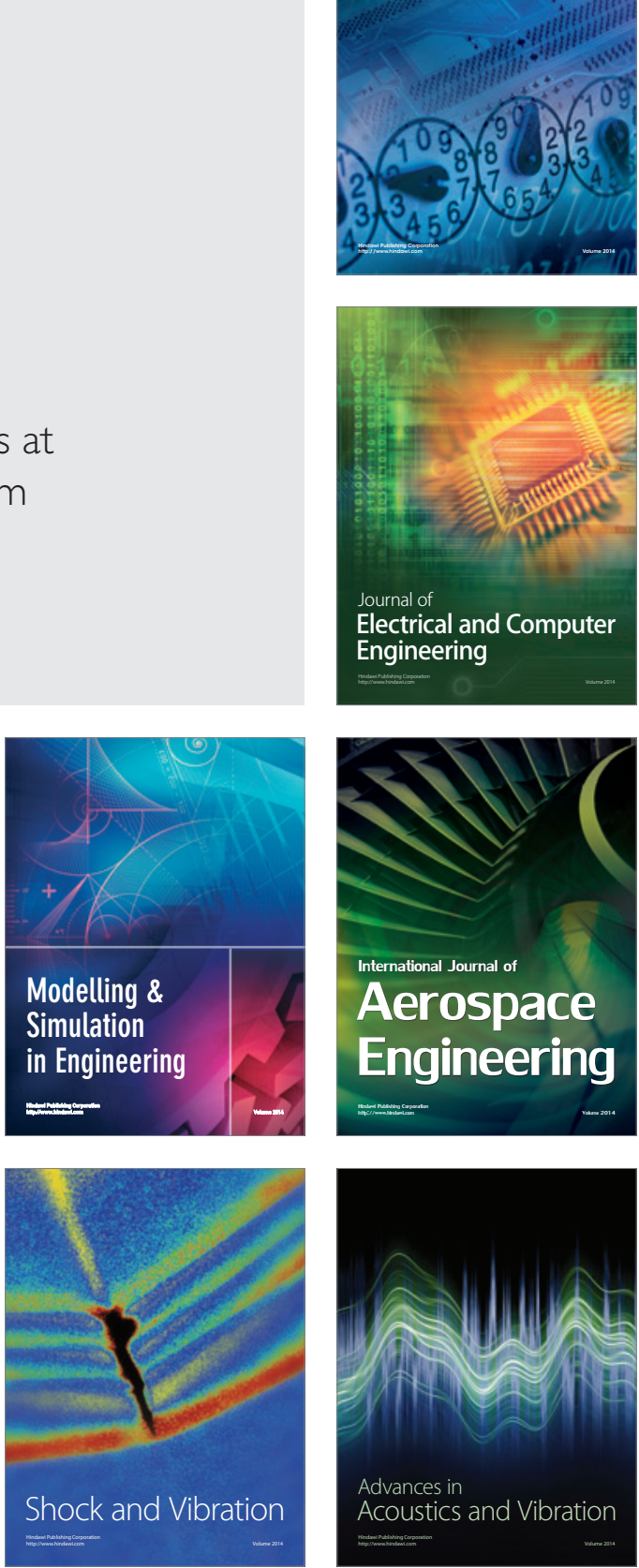